\title{
Investigating the Factors That are Associated With Teachers' Intentions to Utilize Research in Remote Areas of Greece
}

\author{
Dionysios Trikoilis * and Elena C. Papanastasiou \\ School of Education, University of Nicosia, Nicosia, Cyprus
}

Teachers around the world, serving in remote areas experience professional isolation (Bouck, 2004). In addition to being geographically isolated, challenges to remote teaching include a lack of professional support (Ralph, 2002) and experience of social isolation. Yet, the utilization of educational research has the potential to alleviate this issue. Therefore, this study examines the interplay between the factors that can possibly explain the teacher's intentions to use research for professional development purposes in remote schools in Greece. Based on the results of the Structural Equation Model that was examined, research attitudes had the

OPEN ACCESS

Edited by:

Cheryl J. Craig,

Texas A\&M University, United States

Reviewed by:

Balwant Singh,

Partap College of Education, India

Eliza Pinnegar,

Independent Researcher, Orem, UT,

United States

*Correspondence:

Dionysios Trikoilis

trikilis.d@unic.ac.cy

Specialty section:

This article was submitted to

Teacher Education,

a section of the journal

Frontiers in Education

Received: 19 February 2021

Accepted: 30 September 2021

Published: 25 October 2021

Citation:

Trikoilis D and Papanastasiou EC (2021) Investigating the Factors That are Associated With Teachers' Intentions to Utilize Research in

Remote Areas of Greece.

Front. Educ. 6:658011.

doi: 10.3389/feduc.2021.658011 strongest direct relationship to intending to use research for professional development purposes, although research skills also played a major role (directly, and indirectly) in this relationship.

Keywords: educational research, professional development, remote schools, educational inequality, teacher training, attitudes toward research

\section{INTRODUCTION}

Education in remote areas is a worldwide issue (Chunling, 2011) especially since remote areas are home to $46 \%$ of the worldwide population, and to $23 \%$ of the European population. However, serious educational inequalities exist between remote and urban schools (Lingam and Lingam, 2013), which have serious long-term social and economic consequences (Braun et al., 2006).

One of the main educational inequalities that teachers in remote areas face is that of their professional development. Since it is not always easy to travel long distances to attend professional development workshops and presentations (Kelly and Fogarty, 2015), remote teachers miss out on many of the training and other opportunities that are available to teachers in other settings. In turn, this disadvantage leads to serious inequalities since research has consistently shown that effective professional development is strongly linked to improved student outcomes (Smith and Gillespie, 2007; Hattie, 2009) and that it plays a major role in the success of high-performing, high-needs remote schools (Barley and Beesley, 2007). However, very little is known about the factors that are associated with teacher professional development in remote regions, beyond their geographical isolation (Arnold et al., 2005; Glover et al., 2016).

Some research studies have recognized the need for specialized teacher education in remote contexts (Ajayi, 2014; Hudson and Hudson, 2008). Yet the implementation of such programs by universities has been uncoordinated, random, or limited (Sharplin, 2002; White and Reid, 2008). In addition, professional education programs for in-service teachers have all too often been undertheorised and therefore have proved inadequate (Reid et al., 2010).

Despite these obstacles, however, the utilization of research has the potential to alleviate the isolation of teachers in remote areas regarding their professional development. Therefore, this study 


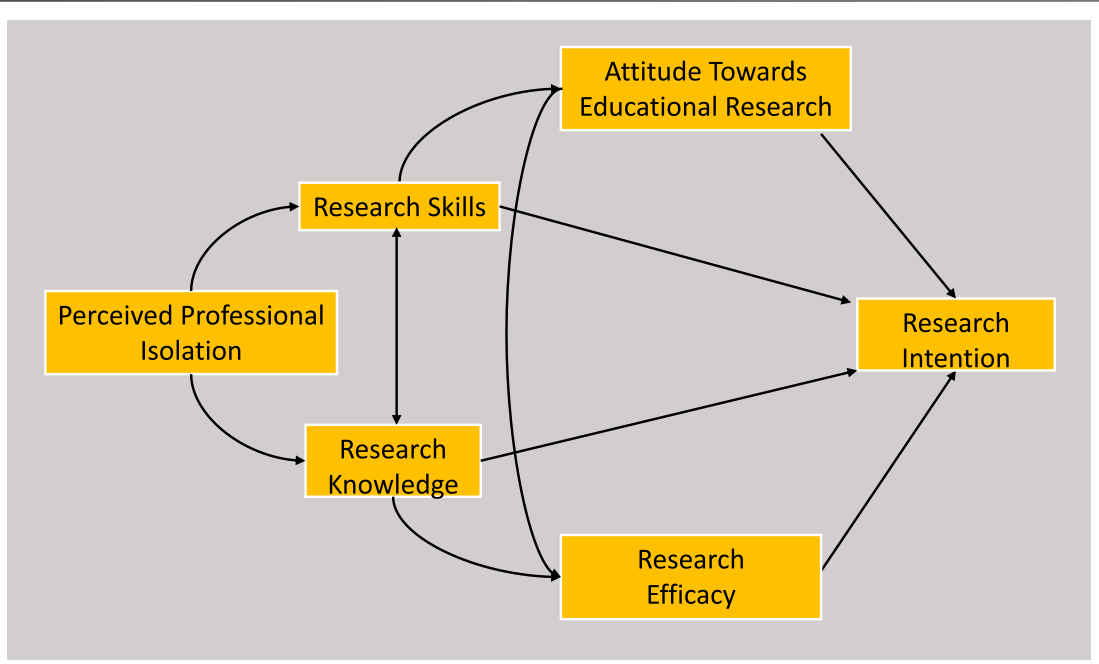

FIGURE 1 | Theoretical model.

examines the interplay between research skills, knowledge, efficacy, and attitudes, concerning teacher's intentions to use research for professional development purposes in remote schools in Greece. Within the Greek context, the research questions of this study are:

1. To what extent are research attitudes, research efficacy, and the perceived professional isolation of remote educators related to their intention to integrate action research into their daily practice?

2. What is the interrelationship between research knowledge, research skills, and research attitudes for teachers in remote schools in Greece?

3. What are the characteristics of remote educators who make the most of educational research in their profession?

\section{Literature Review}

The definition of remote regions in Greece is a bit complex due to the country's particular geographical characteristics. The extent of the Greek mountainous communities accounts for $77.9 \%$ of the country, making Greece among the most mountainous countries of the European Union (NORDREGIO, 2004). Moreover, the majority (63\%) of the population in these areas of Greece live in problematic areas that are severely underdeveloped (European Commission, 2008), have high poverty rates, low levels of education, and lack of access to social services (Eurostat, 2003). This is in addition to the population that lives in remote islands in Greece which corresponds to $22 \%$ of the Greek population (United Nations, 2014).

Remote schools cannot be considered akin to non-remote schools. The education offered in these schools is impacted by many variables such as school poverty. Research reveals that students in remote schools face many personal and educational hardships-from living in poverty to having less opportunity and sophistication in technology. Additionally, school variables, such as school size and school location, matter. School size and location impact many areas of education, including the characteristics of the school, curriculum, and post-school outcomes. Remote schools also have fewer course offerings (Bouck, 2004) and are poorly resourced, exhibiting a minimum standard in school resources (Hungi et al., 2017a). They lack a wide range of physical facilities, equipment, teaching, and learning resources (Lingam and Lingam, 2013). However, the link between the availability of reasonable quality facilities and resources on the one hand, and student learning experiences on the other, is very strong (UNESCO, 2008). Therefore, these deficiencies have a negative impact on how and what children learn (Thomson, 2002; Welch et al., 2007).

The educational inequalities between remote and urban schools create the remote-urban gap which is a troubling social issue. Although there is general agreement on the seriousness of this gap, there is no consensus on its causes or solutions (Fram et al., 2007). Therefore, research reveals that it grows even bigger especially in middle-income countries (Ibourk and Amaghouss, 2012). From an economic perspective, the level of education and its distribution within the population plays a crucial role. It regulates the income distribution and consequently the economic growth. If education is not equally distributed among the population, a large part of the income will be owned by a well-educated minority. This status will raise inequalities in the distribution of incomes, which in turn will cause more poverty (Wang, 1998). For all these reasons educational equity between schools is a subject of national priority (Bouck, 2004) in many countries.

Professional development is another major issue for teachers in remote schools. Their need for professional development increases "substantially" in relevance to the distance from metropolitan and provincial cities (Panizzon and Pegg, 2007). The professional journeys of remote teachers can be fraught with obstacles that their urban counterparts do not have to contend (Warren et al., 2012). Moreover, research has reported feelings of geographical isolation, professional isolation, and social isolation 

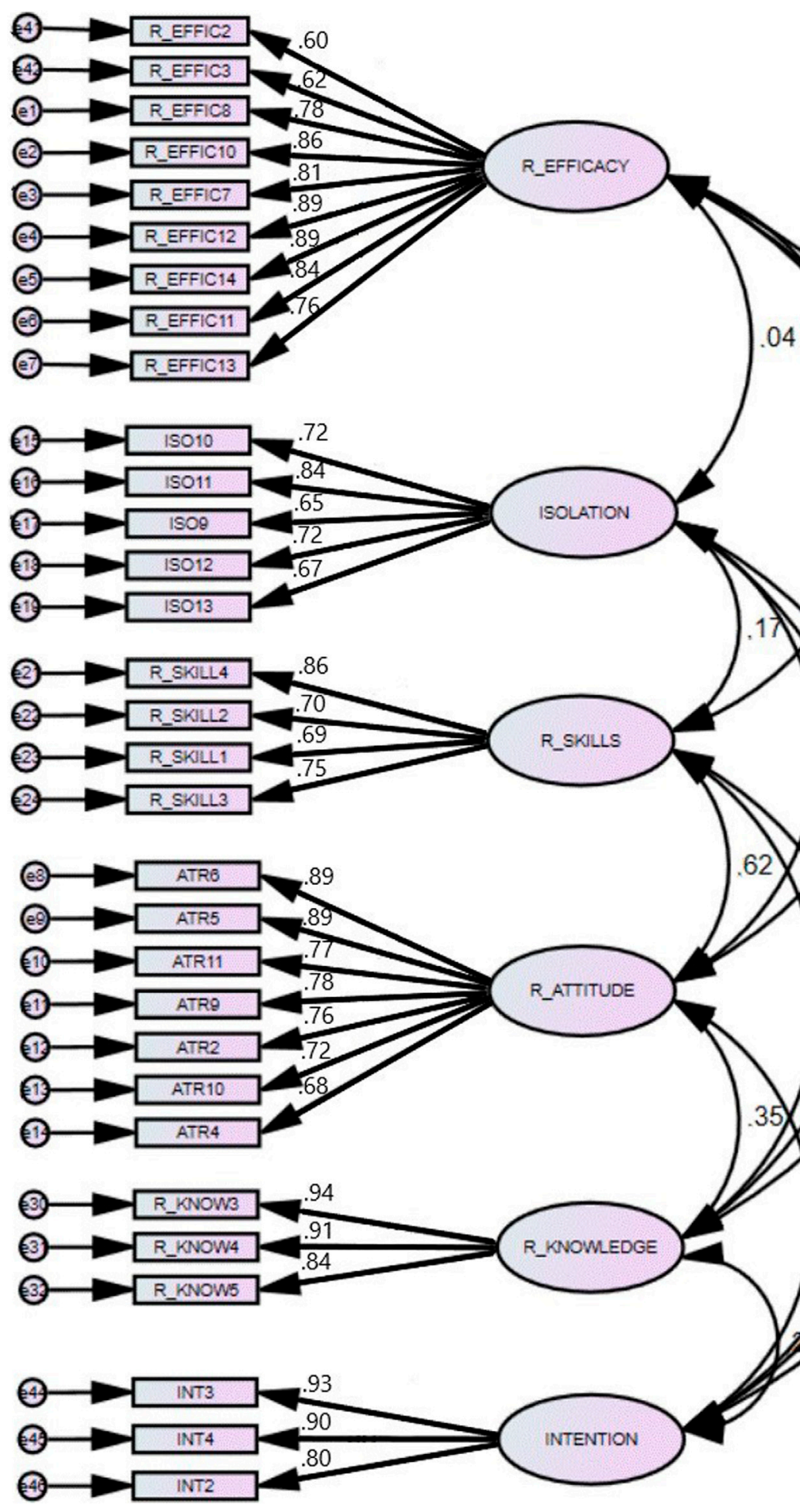

INTENTION

FIGURE 2 | The metric model.

for such teachers (Hellsten et al., 2011). Because of this, teachers in remote schools are six times as likely to report high staff turnover compared to their metropolitan colleagues (Panizzon and Pegg, 2007).
Physical distance has been identified as the major deterrent for teachers in remote settings (Hansen, 2009). It results in experiences of increased difficulties since a lot of professional development is provided centrally in the capital cities of each state 


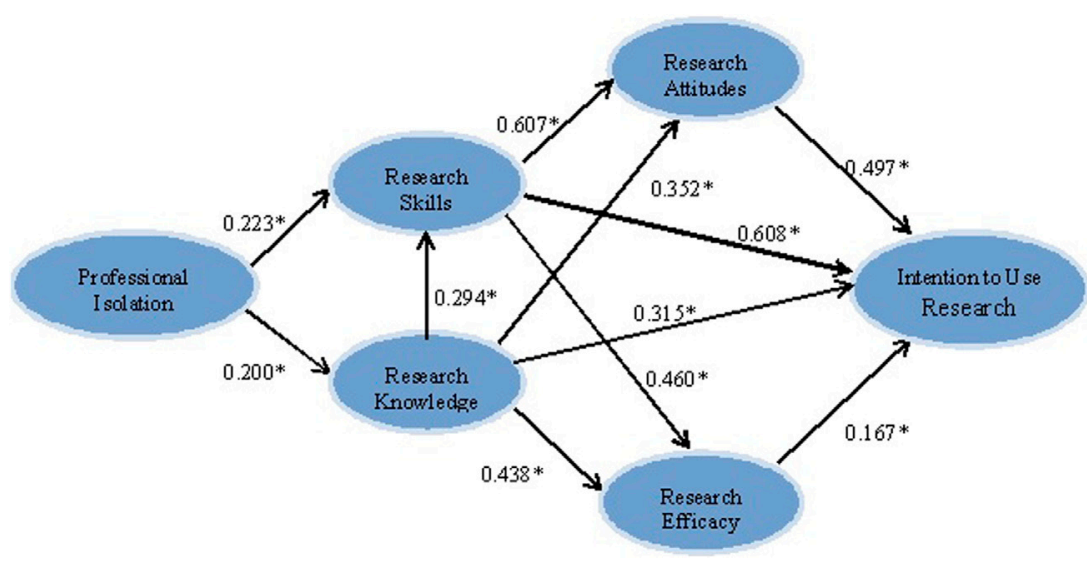

FIGURE 3 | Total estimates between variables $\left({ }^{*} p<0.001\right)$.

following a "one size fits all" metro-centric model to teacher preparation. Yet this is inadequate for the needs of remote schools (White et al., 2011). Therefore teachers are required to travel for lengthy periods to get access to professional development, incurring extra traveling costs that are not always met by central budgets. Due to the geographic isolation of their remote location, teachers also find it difficult to continue with further tertiary studies and keep in touch with the latest teaching issues. This is because of the decreased opportunities to travel to the places that the examinations are held, or because of decreased contact and networking with teachers from other schools (Stokes et al., 1999).

In addition to being geographically isolated, challenges to remote teaching include a lack of professional support (Ralph, 2002) which inevitably results in teachers' professional isolation (Reid et al., 2010; Plunkett and Dyson, 2011). Such teachers have to deal with a lack of teaching resources, insufficient instructional materials (McCoy, 2006), as well as out-of-date classrooms and labs (Lynch, 2000; Marlow and Cooper, 2008). Teachers in remote areas also experience the limited availability of staff to support their PD efforts such as coaches, consultants, substitute teachers for teacher release time (Rude and Brewer, 2003; Hansen, 2009).

Moreover, teachers in remote spaces experience social isolation. They often teach multiple grades, or even multi-grade mixed-age classrooms (Barley, 2009), teach multiple subjects (Beesley et al., 2010), and wear many hats within the school (Minner et al., 2003). This may increase class size, planning time, and workload for them (Hellsten et al., 2011). Lack of facilities as the lack of Internet access and opportunities for socialization seems to make feelings of isolation even worse (Kelly and Fogarty, 2015). Such feelings have been intensified even further during the COVID-19 pandemic (Trikoilis and Papanastasiou, 2020).

Despite the obstacles that are faced by teachers in remote schools, educational research has the potential to enhance their professional development (Ritchie, 2006) without necessarily having to travel long distances to be trained by others. Educational research may offer different functionalities which could affect teachers' practice. First of all research can enable teachers to realize a critical, reflective attitude towards their own practice (Hall, 2009). Secondly, research has the ability to provide teachers with the knowledge and evidence of what and why it works in practice (Ponte et al., 2004). Thirdly, it can foster the transformation of the scientific research results into improvements in classroom practice (Gore and Gitlin, 2004). To fulfill these aims, teachers need to develop sufficient research knowledge and skills, positive beliefs regarding research, and a positive attitude towards research (Linden et al., 2015).

\section{Theoretical Framework}

For the purposes of this study, the theoretical framework that is used is displayed in Figure $\mathbf{1}$ and is based on a hybrid model. It consists of the Theory of Planned Behavior (TPB) (Ajzen, 1991) in conjunction with the theory of Knowledge, Attitude, and Behavior (KAB) (Allport, 1935). The Theory of Planned Behavior argues that intentions are related to factors that motivate and influence behavior. They are indications of the magnitude of the effort that people are planning to make to adopt this behavior (Ajzen, 1991). Intentions also depend on other factors, which can provide a useful model for predicting decisions about one's beliefs and motivations (Hung and Jeng, 2013). According to the Theory of Planned Behavior, the intention to act is determined by three main factors: 1) the individual's attitudes towards specific actions, 2) perceived control, and 3) the subjective norm. In this study, the first factor corresponds to teachers' Attitudes toward Research which includes one's beliefs about the usefulness of research, and their positive predisposition towards research.

Attitudes can be considered as one of the most important concepts in social psychology (Manstead and Hewstone, 1995), which have been used repeatedly to explain human behavior (Zimbardo et al., 1977). According to Fishbein and Ajzen (1975) attitudes are an important factor that is often used to understand and predict people's reaction to a subject or change, and how their behavior may be influenced (Fishbein and Ajzen, 1975). Attitudes constitute a state of readiness of the individual to respond to external stimuli that exert a strong and dynamic influence on cognitive functioning and behavior (Allport, 1935). They also include beliefs about the consequences that behavior can have (Ajzen, 2006). Positive attitudes contribute to progress towards 
TABLE 1 | Reliability and validity of the metric model.

\begin{tabular}{|c|c|c|c|c|c|c|c|c|c|c|}
\hline & CR & AVE & MSV & $\operatorname{Max} R(H)$ & 1 & 2 & 3 & 4 & 5 & 6 \\
\hline Research knowledge & 0.926 & 0.807 & 0.205 & 0.937 & 0.898 & & & & & \\
\hline Research efficacy & 0.936 & 0.624 & 0.417 & 0.971 & 0.453 & 0.790 & & & & \\
\hline Research attitude & 0.919 & 0.620 & 0.446 & 0.979 & 0.347 & 0.646 & 0.787 & & & \\
\hline Proffesional isolation & 0.814 & 0.525 & 0.033 & 0.981 & 0.182 & 0.053 & 0.124 & 0.724 & & \\
\hline Research skills & 0.839 & 0.568 & 0.389 & 0.983 & 0.326 & 0.582 & 0.624 & 0.181 & 0.754 & \\
\hline Research intention & 0.911 & 0.775 & 0.446 & 0.986 & 0.295 & 0.578 & 0.668 & 0.144 & 0.606 & 0.880 \\
\hline
\end{tabular}

TABLE 2 | Factor correlation matrix.

\begin{tabular}{|c|c|c|c|c|c|}
\hline & $\begin{array}{l}\text { Proffesional } \\
\text { isolation }\end{array}$ & Research knowledge & Research skills & Research efficacy & Research attitude \\
\hline Research knowledge & $0.200^{\star \star \star}$ & 0.000 & 0.000 & 0.000 & 0.000 \\
\hline Research skills & $0.223^{\star \star \star}$ & $0.294^{\star \star \star}$ & 0.000 & 0.000 & 0.000 \\
\hline Research efficacy & $0.164^{\star \star \star}$ & $0.438^{\star \star \star}$ & $0.465^{\star \star \star}$ & 0.000 & 0.000 \\
\hline Research attitude & $0.171^{\star \star \star}$ & $0.352^{\star \star \star}$ & $0.607^{\star \star \star}$ & 0.000 & 0.000 \\
\hline Research intention & $0.163^{\star \star \star}$ & $0.315^{\star \star \star}$ & $0.608^{\star \star \star}$ & $0.167^{\star \star \star}$ & $0.497^{\star \star \star}$ \\
\hline
\end{tabular}

${ }^{* * *}\left({ }^{* * *} \mathrm{p}<0.001\right)$

meeting one's goals, while negative attitudes might inhibit these goals. Finally, attitudes ultimately govern one's life by providing directions for managing people and situations (Butt and Shams, 2013).

Teachers' attitudes towards educational research are particularly important and are considered vital to success in any field (Butt and Shams, 2013). It is even argued that attitudes are more important than experience and academic preparation (Abraham, 2003). The findings of various studies have drawn attention to the importance of measuring teachers' attitudes (Yara, 2009), which is a priority because teachers are among the most important practitioners who apply educational theories (Ekiz, 2006; Gu and Wang, 2006; Smith, 2002). Attitudes have the potential to influence teachers' behavior (Richardson, 1996) and to influence the amount of effort they are willing to spend on learning educational research (Papanastasiou, 2005).

The second factor of the TPB corresponds to Perceived behavioral control. This is another parameter that reflects beliefs about individual's perceived ability to perform a behavior (Ajzen, 2006). This term is related to the Self Efficacy Theory - SET (Bandura, 1977). According to this theory, people who consider themselves highly effective behave, think, and feel different from those who perceive themselves as ineffective. The concept of self-sufficiency is related to the judgments a person makes about his or her ability to act in a particular task or circumstance. This perception varies with the period and the situation of the individual (Cervone and Pervin, 2001). Particularly in the case of education, great importance has been given to investigating teachers' self-sufficiency over the last 3 decades (Mahajna, 2014). Researchers have reported that teachers' self-efficacy is related to the desire to teach (Siwatu, 2011), to the level of professional burnout (Skaalvik and Skaalvik, 2010), to the quality of teaching (Raudenbush et al., 1992), commitment to teaching (Skaalvik and Skaalvik, 2010), satisfaction (Klassen and Chiu, 2010) and school climate (Chong et al., 2010). In addition, a person's attitudes toward behavior and sense of self-efficacy can predict one's effort for that behavior (Lillian, 2012).

Subjective norm is an additional factor of the TPB which reflects the personal beliefs that are influenced by society's perception of the application of behavior (Azjen, 2006). That is to say, the individual accepts social pressure and is influenced by the opinion of important people in order to adopt a behavior (Fishbein and Ajzen, 1975). Friends, family, and coworkers are groups that may or may not influence behavior (Chua, 1980). In fact, people are more willing to perform or not to perform a behavior depending on the importance of the social pressure group (Ho et al., 2008). In this study Subjective norm is represented by the teachers' perceived professional isolation. This factor refers to the extent that the remote education community believes that the professional development of teachers is hampered by particular local parameters.

The impact of knowledge on a person's intention is examined through the Knowledge, Attitude, and Behavior theory (KAB). According to the KAB theory, knowledge and information can influence a person's attitudes towards a particular behavior and finally they can achieve a significant impact on the person's behavior (Chou, 2016). According to this theory, knowledge is necessary to make changes in the way individuals acquire knowledge and skills through learning (Liu et al., 2016). Thus, in the context of this study, the term Knowledge is conceptualized by Research Knowledge and Research Skills that have been obtained through teacher preparation courses. According to the KAB model, a teacher's knowledge and skills in research may influence their attitudes toward research which, in turn, may lead to the teacher's engagement in research. Finally, through the combination of these theories an interesting perspective is hypothesized: that Research Knowledge and Research Skills are likely to act as mediators, between Professional Isolation and Research Attitude, but also between Professional Isolation and Research Efficacy. 


\section{MATERIALS AND METHODS}

The sample of this study consisted of 377 teachers from remote mountainous and island regions in Greece. These teachers came from 107 schools (56 primary and 51 secondary) that were randomly selected out of the 556 remote schools of Greece. This sample corresponds to $10.2 \%$ of the population of remote teachers in the country. Overall, $67.9 \%$ of the sample were female, and their average years of teaching were 14.9 years $(\mathrm{SD}=8.3)$. In terms of highest level of education, $52.2 \%$ of the participants only earned a Bachelor's Degree, $44.6 \%$ had a Master's degree, and $3.2 \%$ had earned a Ph.D. in Education.

Six questionnaires were utilized in this study and all items were measured on a 7 -point Likert scale $(1=$ strongly disagree, to $7=$ strongly agree). Two of these questionnaires, the Revised Attitudes Toward Research Scale (R-ATR) (Papanastasiou, 2014; 2005), and The Research Self-efficacy Scale were derived from pre-existing scales while the remaining four were constructed by the researcher. The R-ATR was used to measure teacher attitudes toward research (Papanastasiou, 2014) and had an internal consistency of 0.91 in the current sample. Research self-efficacy was measured by the Research Selfefficacy Scale (Greeley et al., 1989) with an alpha level of 0.96. The intention for action research was measured by the Research Intention Scale $(\alpha=0.91)$. The Professional Isolation Scale was used to measure professional isolation as perceived by remote teachers $(\alpha=0.73)$. The Knowledge Research Scale was used as a measure for each individual's training in research courses and his/her involvement in research $(\alpha=$ 0.95). Finally, the Research Skills Scale was used to measure research practices and skills $(\alpha=0.92)$.

A confirmatory factor analysis was run in AMOS 18 for the Revised Attitudes Toward Research Scale (R-ATR) and The Research Self-efficacy Scale. For the remaining four scales, an exploratory factor analysis had been conducted in SPSS 21 using the Maximum Likelihood extraction method. The Maximum Likelihood estimation was preferred to that of the generalized least squares estimation since it leads to less biased parameter estimates and more accurate fit indices (Olsson et al., 2000). The number of factors extracted was determined by the Eigenvalues and scree plots. The criteria used were eigenvalues greater than 1 as well as the natural breaks in the scree plots. The Oblimin rotation was used in the analysis in order to account for the fact that the underlying factors are most likely correlated with each other.

Moreover, for the purpose of this study, a measurement model consisting of the six scales has been constructed, as displayed in Figure 2, and a two-step approach to Structural equation modeling (SEM) was employed (Schumacker and Lomax, 2010). The first step of this procedure involved the estimation of the measurement model for all latent variables, while the second step involved the examination of the relationships among the latent variables. The fit indices that were used in the analysis were those of the chi-square $\left(\chi^{2}\right)$, the chi-square divided by the degrees of freedom $\left(\chi^{2} / \mathrm{df}\right)$, the Normed Fit Index (NFI), the Tucker-Lewis Index (TLI), the Incremental Fit Index (IFI), the Comparative Fit Index (CFI), and the Root Mean Square Error of Approximation (RMSEA).

\section{RESULTS}

The measurement model was assessed using confirmatory factor analysis (CFA) in AMOS v18. It consisted of 46 items that made the six constructs of the study operational. In order to obtain the good fit of the metric model to the theoretical, the following procedure was followed. Initially, items with a loading factor less than 0.50 and with a poor contribution to the theoretical conceptualization of the corresponding latent variable were removed. The errors of each variable were then examined and co-variations were created between those with the highest values (Hermida, 2015; Gaskin, 2016). After this procedure, each latent variable had to be identified by at least three observed items, characterized by Reliability, Convergence Validity, and Discrimination Validity.

In order to test the verification of Reliability, the Convergence Validation and the Discrimination Validation for this survey, three criteria were used: Composite Reliability (CR), the Average Extracted Variance (AVE), and Maximum Shared Variance (MSV). The first term is a measure of the reliability of internal consistency and consistency of elements of a structural variable. The allowed values for CR are at least 0.7 . The second is a measure of reliability and validity of convergence and expresses the percentage of fluctuation of the structural variable due to variability of the observed variables. Accepted values for AVE are at least 0.5 (Fornell and Lacker, 1981). The third term refers to the maximum value of the dispersion that is shared between the observed variables, making it a criterion for the validity of the distinction. In order to ensure the validity of discrimination, the MSV should be less than AVE, while the square root of the AVE values are greater than the correlation coefficients of the model variables between each other (Hair et al., 2010). Finally, correlations of structural variables should be less than 0.9. All the above criteria were met (Table 1). Composite Reliability values are greater than the threshold of 0.7. Average Expected Variance has values are greater than the minimum of 0.5 (Fornell and Lacker, 1981). Finally, Maximum Shared Variance values are less than the $\mathrm{AVE}$, and the square root of the AVE values are greater than the correlation coefficients between the variables (Hair et al., 2010).

After the estimation of the measurement model, the fit of the hypothesized structural model was examined. The structural model is superior to the measurement model since it can both explain the contribution of the measurable variables to the determination of the model (Byrne, 2001), as well as determine the adaptability of the model to the data (Loehlin, 1987). The results of this analysis revealed an excellent fit of the model based on the following indices: $\mathrm{CMIN} / \mathrm{DF}=2.212$, RMSEA $=0.055, \mathrm{CFI}=0.990 . \mathrm{TLI}=0.982, \mathrm{NFI}=0.991$, and $\mathrm{IFI}=0.995$. The values of the indices indicate that the structural model adequately depicts the relationships between the variables and therefore this model can provide answers to the research questions of this study.

A closer look at the standardized path coefficients of the model, as displayed in Figure 3; Table 2, revealed the following: Teachers with higher levels of Professional Isolation surprisingly demonstrated higher levels of Intention to use Research. This is an indirect effect with a $\beta$-value of $(0.163, p=0.000)$. This 
unexpected finding is supported by the fact that teachers who perceived themselves to have high levels of Professional Isolation were more likely to have higher levels of Research Skills $(\beta=0.223$, $p=0.000)$ and Research Knowledge $(\beta=0.200, p=0.000)$. In turn, teachers with more Research Knowledge reported having more Research Skills $(\beta=0.294, p=0.000)$, higher levels of Research Efficacy $(\beta=0.438, p=0.000)$, higher levels of Research Attitudes $(\beta=0.352, p=0.000)$ and more Intention to use Research $(\beta=$ $0.315, p=0.000)$. This particular finding stresses out the significant role of Research Knowledge as a stimulator of teacher's research intention. Additionally, teachers reporting higher levels of Research Skills were more likely to have positive Attitudes Toward Research $(\beta=0.607, p=0.000)$, higher levels of Research Efficacy $(\beta=0.460, p=0.000)$ and Research Intention $(\beta=0.608, p=0.000)$. This finding underlines the importance of skills gained during the research practice. Finally, teachers with higher levels of Research Attitudes and Research Efficacy reported higher levels of Intention to use research in their daily practice with $\beta$-values of $(\beta=0.497, p=0.000)$ and $(\beta=0.167, p=0.000)$ respectively. According to these results, Research Skills is the variable with the highest direct effect on teacher's intention to use research $(\beta=0.608, p=0.000)$. Research Attitudes $(\beta=0.497$, $p=0.000)$ and Research Knowledge $(\beta=0.315, p=0.000)$ follow by lower $\beta$-values, whereas Research Efficacy has the lowest path coefficient $(\beta=0.167, p=0.000)$.

Beyond the structural model, a series of ANOVAs were performed to investigate the characteristics of the teachers in the study who utilize educational research to the largest extent. However, not many differences were found in relation to their background variables. The only differences were among teacher qualifications, with teachers who held a Master's degree utilizing research to a larger extent compared to those who only held a BA $\left(\bar{x}_{\mathrm{B}}=3.9, \bar{x}_{\mathrm{M}}=4.5, \mathrm{~F}=7.77, p=0.000\right)$. No additional differences were found for teachers holding a Ph.D.

Finally, a series of Spearman's rho Correlations were examined. Based on these correlations, it was found that the intention to utilize research is further associated with their frequency of reading research articles $(\rho=0.54, p=0.000)$ and with their frequency of searching the literature for solving educational problems $(\rho=0.51, p=0.000)$. Moreover, research intention was correlated with the organization of a research process $(\rho=0.475, p=0.000)$, the identification of a research problem $(\rho=0.464, p=0.000)$, the ability to conduct research $(\rho=$ $0.444, p=0.000$ ), the application of educational research findings to solve problems ( $\rho=0.426, p=0.000)$, the communication with other researchers to exchange views on educational issues ( $\rho=$ $0.420, p=0.000)$, the ability to help other researchers to conduct research $(\rho=0.383, p=0.000)$, the completion of postgraduate research courses $(\rho=0.334, p=0.000)$ and finally the completion of courses on the theoretical bases of postgraduate education ( $\rho=$ $0.334, p=0.000)$.

\section{DISCUSSION}

From a theoretical perspective, the data for this study were able to support the fit of the hybrid model which combined the theories of Knowledge, Attitude, and Behavior (KAB) and the Theory of Planned Behavior (TPB). This is in accord with prior research that found that the ability of the TPB theory to collaborate with other theories has been established in a wide range of scientific fields (Hoeksma et al., 2017; Eccles et al., 2012). More specifically, in the current study, the analysis of the final model revealed that the Knowledge construct of the KAB theory can be interpreted by two parameters: Research Knowledge and Research Skills. These two parameters, on the one hand, were correlated to Attitudes toward Research according to the $\mathrm{KAB}$ theory whereas on the other hand they were implemented in the TPB model as mediators between Professional Isolation, Attitudes toward Research and Research Skills.

The results of this study also underlined the importance of the teacher's theoretical knowledge and research practice skills. Specifically, although Skills, Knowledge, Attitudes, and Research Efficacy were positively related to teacher's Intentions to use Research, Research Skills and Research Attitudes were the ones that had the largest effect on this Intention. These results underline the role of academic knowledge in shaping teacher's attitudes towards research, but far more emphasize the contribution of practical research skills. The findings are in line with other surveys which indicate that students who acquire theoretical and practical knowledge of research show an improvement in their research efficacy (Bishop and Bieschke, 1998; Tosun, 2014).

Beyond the theoretical perspective, an especially interesting finding of this study was that the teachers who perceived themselves as the most isolated professionally also had higher levels of Research Knowledge and Skills. This outcome could be explained by the John Henry Effect; So, it is likely that these teachers, who are aware that they are lagging behind in terms of their qualifications in relation to their colleagues in urban centers, might try especially hard to develop professionally on their own in order to meet the country's teacher evaluation criteria. It is no coincidence that $44.6 \%$ of the sample holds a Master's degree and $3.2 \%$ holds a Ph.D. in education.

In terms of teacher's characteristics, there was a difference in the intention of doing research between teachers holding a postgraduate degree and those who only hold a bachelor's degree. This result is also consistent with other prior research that has found that students in postgraduate education are more likely to have positive attitudes and utilize research to a larger extent compared to teachers with only bachelor degrees (Bishop and Bieschke, 1998; Holincheck and Galluzzo, 2012; Kurt, 2015). This is also consistent with prior studies that found that teachers who had taken research courses at both, the graduate and undergraduate level were more likely to read research articles compared to those who only took one research course at a single point in their educational training (Papanastasiou and Karagiorgi, 2019). For this reason, several educational institutions are re-examining the way they prepare their postgraduate students and redefining research requirements in postgraduate studies (Bishop and Bieschke, 1998; Metz, 2001; Eisenhart and DeHaan, 2005).

The results of this study raise several implications regarding the professional development of teachers in remote areas. In this friendly climate, teacher's professional experience can be used to 
develop action research through successful and continuous collaborative practices (Chance and Segura, 2009). However, the inability to save time is one of the major barriers to teacher research involvement (Goswami and Rutherford, 2009; Peterson et al., 2010). Therefore at the service level, it is necessary to restructure the school schedule to make provision for time devoted to research activities, both by teachers and students. Redesigning teacher's responsibilities and hiring auxiliary staff at school could also save time and energy for engaging in educational research.

In addition, the problem of distance from urban centers and the sense of professional isolation of teachers in remote schools can be addressed by offering distance education research programs. According to the results of the analysis, there are mediators that mediate not only between Professional Isolation and Research Attitudes but also between Professional Isolation and Research Self-Efficacy. These mediators are Research Knowledge and Research Skills and can help shape educational training programs (seminars, webinars, and workshops) for remote in-service teachers. These programs need to place particular emphasis on the development of research skills in relation to theoretical knowledge, as the former are more strongly linked to the intention to do research, both directly and indirectly.

The findings of this study could also shed light to some implications both at undergraduate and graduate-level education. Keeping toward research is less influenced by theoretical knowledge of research and much more by research skills, a different orientation for the education of the future teacher-researchers should be defined. On this basis, the adoption of a practical perspective regarding teacher research training would allow teachers to undertake research more effectively (Papanastasiou and Karagiorgi, 2019). Therefore, academic institutions could focus on inducting new teachers early into the education research culture (Frager, 2010). This will help young researchers understand the importance of research from the beginning of their studies so that they can integrate into the learning community as independent and critical thinkers and researchers (Merkel, 2003). This practice could also reinforce student's interest in research, encouraging them to create their own research agenda in order to create new knowledge as well as preparing them for postgraduate programs (Adamsen et al., 2003). Undergraduate students can also participate in summer undergraduate research programs. These programs strengthen their self-confidence and increase their enthusiasm for scientific research (Brey et al., 2015).

Additionally, the research course syllabus for both undergraduate and postgraduate students could focus more on the development of skills which this study found to be highly correlated with the intention for research. These skills refer to the reading of research articles and searching the literature in order to solve educational problems. Other research-oriented skills are the organization of the research process, the identification of a research problem, and the ability to conduct research. The application of educational research findings to solve problems, the communication with other researchers to exchange views on educational issues, the ability to help other researchers conduct research and the completion of postgraduate research courses were found to have strong correlations with the intention for research. Finally, as the results of this study show, teachers' intentions to do research can be further enhanced by courses on the theoretical foundations of education. These courses can provide the necessary background of knowledge they need in order to get familiar with the existing theories of the field and mobilize their own professional quest in research.

In conclusion, this study can provide useful information to universities and policymakers regarding teacher professional development. On the one hand, this study supports the potential of educational research for the purposes of the professional development of teachers in remote areas around the world. On the other hand, this study supports the importance of providing incentives to teachers in remote areas to obtain postgraduate degrees which could advance their research knowledge and help them develop more concrete research skills. This in turn could possibly have a positive impact on their research attitudes as well as on their research efficacy, which could be used in ways to improve the knowledge, skills, as well as their teaching practices, without passively expecting others to offer professional development opportunities to them.

\section{DATA AVAILABILITY STATEMENT}

The raw data supporting the conclusions of this article will be made available by the authors, without undue reservation.

\section{ETHICS STATEMENT}

The studies involving human participants were reviewed and approved by Greek Board of the Institute of Educational Policy. Written informed consent for participation was not required for this study in accordance with the national legislation and the institutional requirements.

\section{AUTHOR CONTRIBUTIONS}

Both authors have contributed to the concept and the design of the research project. The data collection, analysis and write-up was performed by DT, while the supervision and critical review was performed by EP. Both authors have reviewed, read and approved this manuscript for publication.

\section{ACKNOWLEDGMENTS}

The main findings of this manuscript arise from the doctoral thesis submitted to the University of Nicosia (Trikoilis and Papanastasiou, 2019). 


\section{REFERENCES}

Abraham, J. (2003). Positive Attitude. Available at: http://www.thedominican.net/ articles/attitude.htm (Accessed November 20, 2016).

Adamsen, L., Larsen, K., Bjerregaard, L., and Madsen, J. K. (2003). Moving Forward in a Role as a Researcher: the Effect of a Research Method Course on Nurse's Research Activity. J. Clin. Nurs. 12 (3), 442-450. doi:10.1046/j.1365-2702.2003.00708.x

Ajayi, L. (2014). Investigating Effective Teaching Methods for a Place-Based Teacher Preparation in a Rural Community. Educ. Res. Pol. Prac 13 (3), 251-268. doi:10.1007/s10671-014-9162-z

Ajzen, I. (2006). Constructing a TpB Questionnaire: Conceptual and Methodological Considerations. Available at: https://people.umass.edu/ aizen/tpb.html (Accessed September 20, 2018).

Ajzen, I. (1991). The Theory of Planned Behavior. Organizational Behav. Hum. Decis. Process. 50, 179-211. doi:10.1016/0749-5978(91)90020-T

Allport, G. W. (1935). “Attitudes," in In Handbook of Social Psychology. Editor C. Murchison (Worcester, MA: Clark Univ. Press)), 798-844.

Arnold, M., Newman, J. H., Gaddy, B. B., and Dean, C. B. (2005). A Look at the Condition of Remote Education Research: Setting a Direction for Future Research. J. Res. Remote Edu. 20, 6. doi:10.1080/02671522.2005.10738232

Ash Merkel, C. (2003). Undergraduate Research at the Research Universities. New Dir. Teach. Learn. 2003 (93), 39-54. doi:10.1002/tl.87

Bandura, A. (1977). Self-efficacy: Toward a Unifying Theory of Behavioral Change. Psychol. Rev. 84 (2), 191-215. doi:10.1037/0033-295X.84.2.191

Barley, Z. A., and Beesley, A. D. (2007). Remote School success: What Can We Learn? J. Res. Remote Edu. 22, 1-16.

Barley, Z. A. (2009). Preparing Teachers for Rural Appointments: Lessons from the Mid-continent. Rural Educator 30 (3), 10-15. doi:10.35608/ruraled.v30i3.444

Beesley, A. D., Atwill, K., Blair, P., and Barley, Z. A. (2010). Strategies for Recruitment and Retention of Secondary Teachers in central U.S. Rural Schools. Rural Educator 3 (2), 1-9.

Bishop, R. M., and Bieschke, K. J. (1998). Applying Social Cognitive Theory to Interest in Research Among Counseling Psychology Doctoral Students: A Path Analysis. J. Couns. Psychol. 45, 182-188. doi:10.1037/0022-0167.45.2.182

Bouck, E. C. (2004). How Size and Setting Impact Education in Remote Schools. Remote Educator 25 (3), 38-42. doi:10.1177/07419325040250060401

Braun, H. I., Wang, A., Jenkins, F., and Weinbaum, E. (2006). The Black-White Achievement gap: Do State Policies Matter? Edu. Pol. Anal. Arch. 14 (8), 1-110. doi:10.14507/epaa.v14n8.2006

Brey, E., Campanile, M., and Lederman, N. (2015). Evaluation of a Nine Year Summer Undergraduate Research Program in Biomedical Engineering. Paper presented at 122nd ASEE Annual Conference \& Exposition June 14-17, 2015 Seattle. WA. doi:10.18260/p.24032

Butt, I. H., and Shams, J. A. (2013). Master in Education Student Attitudes towards Research: A Comparison between Two Public Sector Universities in Punjab. South Asian Stud. 28 (1), 97-105

Byrne, B. M. (2001). Structural Equation Modeling with AMOS: Basic Concepts, Applications, and Programming. Mahwah, NJ: Lawrence Erlbaum Associates.

Cervone, D., and Pervin, L. A. (2001). Personality Theories, Research and Applications. Athens: Gutenberg.

Chance, P. L., and Segura, S. N. (2009). A Rural High School's Collaborative Approach to School Improvement. J. Res. Rural Edu. 24 (5), 1-12.

Chong, W. H., Klassen, R. M., Huan, V. S., Wong, I., and Kates, A. D. (2010). The Relationships Among School Types, Teacher Efficacy Beliefs, and Academic Climate: Perspective from Asian Middle Schools. J. Educ. Res. 103 (3), 183-190. doi:10.1080/00220670903382954

Chou, P. (2016). A Study of Knowledge, Attitudes, and Behavior for the University Students to Choose Abroad the Trip. Int. J. Res. 3 (9), 101-103.

Chua, E. K. (1980). Consumer Intention to Deposit at Banks: An Empirical Investigation of its Relationship with Attitude, Normative Belief and Confidence. Singapore: Academic Exercise, Faculty of Business Administration, National University of Singapore.

Chunling, L. (2011). Shuju wucha de tiaozheng xiaoguo de pinggu (Evaluation of results of adjusting data error margins). Shehuixue yanjiu (Sociological Studies) 3.

Eccles, M. P., Grimshaw, J. M., MacLennan, G., Bonetti, D., Glidewell, L., Pitts, N. B., et al. (2012). Explaining Clinical Behaviors Using Multiple Theoretical Models. Implement Sci. 7 (1), 99-111. doi:10.1186/1748-5908-7-99
Eisenhart, M., and DeHaan, R. L. (2005). Doctoral Preparation of Scientifically Based Education Researchers. Educ. Res. 34 (4), 3-13. doi:10.3102/ 0013189X034004003

Ekiz, D. (2006). Primary School Teacher's Attitudes towards Educational Research. Educ. Sci. Theor. Pract. 6 (2), 373-402.

European Commission (2008). Poverty and Social Exclusion in Remote Areas. Final Report, Annex I. Country Studies:Greece. Luxembourg: Office for Official Publications of the European Communities.

Eurostat (2003). "Poverty and Social Exclusion in the EU after Laeken-Part 1 and Part 2", Statistics in Focus, population and Social Conditions. THEME 3-8/2003 and $9 / 2003$. Brussels.

Fishbein, M., and Ajzen, I. (1975). Belief, Attitude, Intention and Behaviour: An Introduction to Theory and Research. London: Addison-Wesley.

Fornell, C., and Larcker, D. F. (1981). Evaluating Structural Equation Models with Unobservable Variables and Measurement Error. J. Marketing Res. 18 (1), 39-50. doi:10.2307/315131210.1177/002224378101800104

Frager, A. M. (2010). Helping Preservice reading Teachers Learn to Read and Conduct Research to Inform Their Instruction. J. Adolesc. Adult Literacy 54, 199-208. doi:10.1598/jaal.54.3.5

Fram, M. S., Miller-Cribbs, J. E., and Van Horn, L. (2007). Poverty, Race, and the Contexts of Achievement: Examining Educational Experiences of Children in the U.S. South. Soc. Work 52 (4), 309-319. doi:10.1093/sw/52.4.309

Gaskin, J. (2016). Modification Indices. Available at: http://statwiki.kolobkreations. com (Accessed August 28, 2018).

Glover, T. A., Nugent, G. C., Chumney, F. L., Ihlo, T., Shapiro, E. S., Guard, K., et al. (2016). Investigating Remote Teacher's Professional Development, Instructional Knowledge, and Classroom Practice. J. Res. Remote Edu. 31 (3), 1-16.

Goswami, D., and Rutherford, M. (2009). "What's Going on Here? Seeking Answers through Teacher Inquiry," in In Teacher Inquiry: Approaches to Language and Literacy Research. Editors D. Goswami, C. Lewis, M. Rutherford, and D. Waff (New York, NY: Teachers College Press), 1-11.

Greeley, A. T., Johnson, E., Seem, S., Braver, M., Dias, L., Evans, K., et al. (1989). Research Self-Efficacy Scale: Unpublished Scale. Pennsylvania: The Pennsylvania State University.

Gu, L., and Wang, J. (2006). School-based Research and Professional Learning: An Innovative Model to Promote Teacher Professional Development in China1. Teach. Edu. 17 (1), 59-73. doi:10.1080/10476210500528079

Hair, J., Black, W., Babin, B., and Anderson, R. (2010). Multivariate Data Analysis. 7th ed. Upper Saddle River, NJ, USA: Prentice-Hall.

Hall, E. (2009). Engaging in and Engaging with Research: Teacher Inquiry and Development. Teach. Teach. 15 (6), 669-681. doi:10.1080/ 13540600903356985

Hansen, J. W. (2009). Professional Development in Rural Public Schools: A Review of Literature. [dissertation]. Marquette, MI: Northern Michigan University.

Hattie, J. (2009). Visible Learning: A Synthesis of over 800 Meta-Analyses Relating to Achievement. New York: Routledge.

Hellsten, L. M., McIntyre, L. J., and Prytula, M. P. (2011). Teaching in Rural Saskatchewan: First Year Teachers Identify Challenges and Make Recommendations. Rural Educator 32 (3), 11-21. doi:10.35608/ ruraled.v32i3.425

Hermida, R. (2015). The Problem of Allowing Correlated Errors in Structural Equation Modeling: Concerns and Considerations. Comput. Methods Soc. Sci. 3, 5.

Ho, S. S., Lee, W., and Shahiraa Sahul Hameed, S. S. (2008). Muslim Surfers on the Internet: Using the Theory of Planned Behaviour to Examine the Factors Influencing Engagement in Online Religious Activities. New Media Soc. 10, 93-113. doi:10.1177/1461444807085323

Hoeksma, D. L., Gerritzen, M. A., Lokhorst, A. M., and Poortvliet, P. M. (2017). An Extended Theory of Planned Behavior to Predict Consumer's Willingness to Buy mobile slaughter Unit Meat. Meat Sci. 128, 15-23. doi:10.1016/ j.meatsci.2017.01.011

Holincheck, N., and Galluzzo, G. (2012). Updating and Validating a Teachers' Attitude toward Education Research Scale. Vancouver: at the American Educational Research Association.

Hudson, P., and Hudson, S. (2008). Sustainable Futures for Remote Education: Changing Preservice Teachers' Attitudes for Teaching in Remote Schools. Paper presented at the Australian Association of Research in Education (AARE) Conference. Brisbane, Australia. 
Hung, W.-C., and Jeng, I. (2013). Factors Influencing Future Educational Technologists' Intentions to Participate in Online Teaching. Br. J. Educ. Technol. 44 (2), 255-272. doi:10.1111/j.1467-8535.2012.01294.x

Hungi, N., Ngware, M., Mahuro, G., and Muhia, N. (2017a). Learning Barriers Among Grade 6 Pupils Attending Rural Schools in Uganda: Implications to Policy and Practice. Educ. Res. Pol. Prac 16, 129-155. doi:10.1007/s10671-0169199-2

Ibourk, A., and Amaghouss, J. (2012). Measuring Education Inequalities: Concentration and Dispersion-Based Approach-Lessons from Kuznets Curve in MENA Region-. Wje 2 (6), 51-65. doi:10.5430/wje.v2n6p51

Kelly, N., and Fogarty, R. (2015). An Integrated Approach to Attracting and Retaining Teachers in Remote and Remote Parts of Australia. J. Econ. Soc. Pol. 17, 1.

Klassen, R. M., and Chiu, M. M. (2010). Effects on Teachers' Self-Efficacy and Job Satisfaction: Teacher Gender, Years of Experience, and Job Stress. J. Educ. Psychol. 102 (3), 741-756. doi:10.1037/a0019237

Lillian, K. Y. (2012). A Study of the Attitude, Self Efficacy, Effort and Academic Achievement of City Students towards Research Methods and Statistics. Discovery-SS Student E-l 1, 154-183.

Lingam, G. I., and Lingam, N. (2013). Making Learning and Teaching a Richer Experience: A challenge for Remote Fijian Primary Schools. Educ. Res. Rev. 8 (21), 2160-2168. doi:10.5897/ERR2013.1622

Liu, L., Liu, Y. P., Wang, J., An, L. W., and Jiao, J. M. (2016). Use of a KnowledgeAttitude-Behaviour Education Programme for Chinese Adults Undergoing Maintenance Haemodialysis: Randomized Controlled Trial. J. Int. Med. Res. 44, 557-568. doi:10.1177/0300060515604980

Loehlin, J. C. (1987). Latent Variable Models: An Introduction to Factor, Path, and Structural Analysis. Hillsdale, N J: Erlbaum.

Lynch, S. J. (2000). Equity and Science Education Reform. Mahwah, NJ: Erlbaum.

Mahajna, S. (2014). "On the Way to School": Structural Analysis of the Relational Path between Social Context Variables and Teachers' Self-Efficacy Among Preservice Palestinian Teachers in Israel. Ajte 39, 4. doi:10.14221/ajte.2014v39n4.9

Manstead, A., and Hewstone, M. (1995). Attitude Theory and Researchthe Blackwell Encyclopedia of Social Psychology Oxford: Blackwell, 47-52.

Marlow, D., and Cooper, M. (2008). The MetLife Survey of the American Teacher: Past, Present and Future. New York, NY: Metlife.

McCoy, L. P. (2006). Southern Rural Public Schools: A Study of Teacher Perspectives. Qual. Rep. 11 (4), 749-763.

Metz, M. H. (2001). Intellectual Border Crossing in Graduate Education: A Report from the Field. Educ. Res. 30 (5), 1-7. doi:10.3102/0013189X030005012

Minner, D., Berns, B., Century, J. R., and Hiles, E. (2003). Science Education Reform in Rural America: A Snapshot. Newton, MA: Education Development Center.

Murat, K. (2015). The Teachers Research Self-Efficacy and Attitudes towards Scientific Research Based on Different Parameters: A Case Study of Agri Province. Educ. Res. Rev. 10 (14), 1922-1929. doi:10.5897/ERR2015.2291

NORDREGIO (2004). Mountain Areas in Europe: Analysis of Mountain Areas in EU Member States, Acceding and Other European Countries, Sweden: European Commission contract No 2002, CE.16.0.AT.136, Final report.

Olsson, U. H., Foss, T., Troye, S. V., and Howell, R. D. (2000). The Performance of ML, GLS, and WLS Estimation in Structural Equation Modeling under Conditions of Misspecification and Nonnormality. Struct. Equation Model. A Multidisciplinary J. 7, 557-595. doi:10.1207/s15328007sem0704_3

Panizzon, D., and Pegg, J. (2007). Chasms in Student Achievement: Exploring the Rural-Metropolitan divide. Edu. Rural Aust. 17 (2), 3-20.

Papanastasiou, E. C. (2005). Factor Structure of the Attitudes towards Research Scale. Stat. Edu. Res. J. 4 (1), 16-26. doi:10.1037/t64085-000

Papanastasiou, E. C., and Karagiorgi, Y. (2019). The Involvement of School Teachers in Research-related Activities: Extent, Quality and Predictors. Eur. J. Educ. 54, 621-634. doi:10.1111/ejed.12364

Papanastasiou, E. C. (2014). Revised-Attitudes toward Research Scale (R-ATR); A First Look at its Psychometric Properties. J. Res. Edu. 24 (2), 146-159. doi:10.1037/t35506-000

Peterson, S. S., Marks Krpan, C., and Swartz, L. (2010). University Faculty, Colleagues and Teachers' Federation as Mentors in Collaborative Action Research. McGill J. Edu. 45 (2), 257-274. doi:10.7202/045607ar

Plunkett, M., and Dyson, M. (2011). Becoming a Teacher and Staying One: Examining the Complex Ecologies Associated with Educating and Retaining New Teachers in Rural Australia? Ajte 36 (1), 3. doi:10.14221/ajte.2011v36n1.3
Ponte, P., Ax, J., Beijaard, D., and Wubbels, T. (2004). Teachers' Development of Professional Knowledge through Action Research and the Facilitation of This by Teacher Educators. Teach. Teach. Edu. 20 (6), 571-588. doi:10.1016/j.tate.2004.06.003

Ralph, E. G. (2002). Teaching in Rural Schools: A Synthesis of Interns and Cooperating Teachers' Views. Rural Educator 24 (2), 13-22.

Raudenbush, S. W., Bhumirat, C., and Kamali, M. (1992). Predictors and Consequences of Primary Teachers' Sense of Efficacy and Students' Perceptions of Teaching Quality in Thailand. Int. J. Educ. Res. 17 (2), 165-177. doi:10.1016/0883-0355(92)90006-R

Reid, J.-A., Green, B., Cooper, M., Hastings, W., Lock, G., and White, S. (2010). Regenerating Rural Social Space? Teacher Education for Rural-Regional Sustainability. Aust. J. Edu. 54 (3), 262-276. doi:10.1177/ 000494411005400304

Richardson, V. (1996). "The Role of Attitudes and Beliefs in Learning to Teach," in In Handbook of Research on Teacher Education. Editor J. Sikula (New York: Macmillan), 102-119.

Ritchie, G. V. (2006). Teacher Research as a Habit of Mind. [dissertation]. Virginia: George Mason University.

Rude, H. A., and Brewer, R. D. (2003). Assessment of Professional Development Systems: Improving Rural Special Education Services. Rural Spec. Edu. Q. 22 (4), 20-28. doi:10.1177/875687050302200404

Schumacker, R., and Lomax, R. (2010). A Beginner's Guide to Structural Equation Modeling. 3rd ed. New York, NY: Routledge.

Sharplin, E. D. (2002). Remote Retreat or Outback Hell: Preservice Teachers' Expectations of Remote and Remote Teaching. Issues Educ. Res. 12 (1), 49-63.

Siwatu, K. O. (2011). Preservice Teachers' Sense of Preparedness and Self-Efficacy to Teach in America's Urban and Suburban Schools: Does Context Matter? Teach. Teach. Edu. 27 (2), 357-365. doi:10.1016/j.tate.2010.09.004

Skaalvik, E. M., and Skaalvik, S. (2010). Teacher Self-Efficacy and Teacher Burnout: A Study of Relations. Teach. Teach. Edu. 26 (4), 1059-1069. doi:10.1016/ j.tate.2009.11.001

Smith, C. A. (2002). Supporting Teacher and School Development: Learning and Teaching Policies, Shared Living Theories and Teacher-Researcher Partnerships. Teach. Dev. 6 (2), 157-179. doi:10.1080/13664530200200163

Smith, C., and Gillespie, M. (2007). "Research on Professional Development and Teacher Change: Implications for Adult Basic Education," in In Review of Adult Learning and Literacy. Editors J. Comings, B. Garner, and C. Smith (New Jersey: Lawrence Erlbaum Associates), 205-245.

Stokes, H., Stafford, J., and Holdsworth, R. (1999). Rural and Remote School Education: A Survey for the Human Rights and Equal Opportunities Commission. Melbourne: Youth Research Centre, University of Melbourne.

Thomson, P. (2002). Schooling the Rustbelt Kids: Making the Difference in Changing Times. New South Wales, Australia: Allen \& Unwin.

Tosun, C. (2014). Pre-Service Teachers' Opinions about the Course on Scientific Research Methods and the Levels of Knowledge and Skills They Gained in This Course. Aust. J. Teach. Edu. 39, 10. doi:10.14221/ajte.2014v39n10.7

Trikoilis, D., and Papanastasiou, E. C. (2020). The Potential of Research for Professional Development in Isolated Settings during the COVID-19 Crisis and beyond. J. Technol. Teach. Educ. 28 (2), 295-300.

UNESCO (2008). Overcoming Inequality: Why Governance Matters. Education for All Global Monitoring Report 20089. Oxford/ParisOxford: UNESCOUniversity Press.

United Nations (2014). 2014 Revision of the World Urbanization Prospects. Latest Major Publications-United Nations Department of Economic and Social Affairs. https://www.un.org/en/development/desa/publications/ 2014-revision-worldurbanization-prospects.html.

van der Linden, W., Bakx, A., Ros, A., Beijaard, D., and van den Bergh, L. (2015). The Development of Student Teachers' Research Knowledge, Beliefs and Attitude. J. Edu. Teach. 41 (1), 4-18. doi:10.1080/02607476.2014.992631

Warren, E. A., Quine, J., and DeVries, E. (2012). Supporting Teachers' Professional Learning at a Distance: A Model for Change in Atrisk Contexts. Aust. J. Teach. Edu. 37, 6. doi:10.14221/ajte.2012v37n6.1

Welch, A., Helme, S., and Lamb, S. (2007). in "Rurality and Inequality in Education," in International Studies in Educational Inequality, Theory and Policy. Editors R. Teese, S. Lamb, M. Duru-Bellat, and S. Helme (Dordrecht): Springer).

White, S., Lock, G., Hastings, W., Cooper, M., Reid, J., and Green, B. (2011). Investing in Sustainable and Resilient Rural Social Space: Lessons for Teacher Education'. Edu. Rural Aust. 21, 67-78. 
White, S., and Reid, J. (2008). Placing Teachers? Sustaining Remote Schooling through Place-Consciousness in Teacher Education. J. Res. Remote Edu. 23 (7), $1-11$.

Yara, P. O. (2009). Student's Attitude towards Mathematics and Academic Achievement in Some Selected Secondary Schools in South Western Nigeria. Eur. J. Scientific Res. 36 (3), 336-341.

Zimbardo, P., Ebbesen, E., and Maslach, C. (1977). Influencing Attitudes and Changing Behaviour. Reading, MA: Addison-Wesley.

Conflict of Interest: The authors declare that the research was conducted in the absence of any commercial or financial relationships that could be construed as a potential conflict of interest.
Publisher's Note: All claims expressed in this article are solely those of the authors and do not necessarily represent those of their affiliated organizations, or those of the publisher, the editors, and the reviewers. Any product that may be evaluated in this article, or claim that may be made by its manufacturer, is not guaranteed or endorsed by the publisher.

Copyright (C) 2021 Trikoilis and Papanastasiou. This is an open-access article distributed under the terms of the Creative Commons Attribution License (CC $B Y)$. The use, distribution or reproduction in other forums is permitted, provided the original author(s) and the copyright owner(s) are credited and that the original publication in this journal is cited, in accordance with accepted academic practice. No use, distribution or reproduction is permitted which does not comply with these terms. 